\title{
Comprehensive Exploration and three-dimensional construction technology of water plug based on directional horizontal drilling caved column
}

\author{
Gan $\operatorname{Tian}^{1 *}$ \\ ${ }^{1}$ Xi' an Research Institute of China Coal Technology \& Engineering Group, Xi'an City, Shaanxi Provence, China
}

\begin{abstract}
The ordovician limestone water inrush accident occurred during the excavation of 8228 working face in Tashan Coal Mine, Tongmei Group. On the basis of comprehensive geophysical exploration above and below the well, in order to find out the development boundary of the water flowing subsided column and the distribution characteristics of the broken body filled in it, and to control the subsided column by Grouting, the development boundary, the influence zone, the cementation of the fractured body and the distribution characteristics of the water flowing subsided column are found out by means of multi-layer and multi-branch surface directional horizontal drilling speed logging, drilling fluid leakage, cuttings logging and logging while drilling, and combined with data statistical analysis. The length and short axis of the collapse column is $410 \mathrm{~m}$ $\sim 200 \mathrm{~m}$, and the broken area is mainly distributed in the right front of the driving head of the belt roadway near the water inrush roadway. The $3 \mathrm{~d}$ geological modeling of the spatial structure and development characteristics of the collapse column is carried out by using SURPAC software, and the main passageway area, fracture area and secondary fracture area are divided according to the crushing degree of the collapse column filling material. In view of the different zones of the collapse column broken body, the directional horizontal drilling control technology and the three-dimensional block grouting technology are used to construct the separate zones of the grouting technology. The safe mining of the working face is finally realized by the comprehensive treatment of cutting the source and reinforcing the water-flowing collapse column. The comprehensive exploration and treatment technology of directional horizontal drilling multi-branch collapse column provides a good reference for other similar projects.
\end{abstract}

\section{Introduction}

Karst water hazard is one of the main water hazards affecting the safety production of coal mines in China. With the gradual depletion of China's shallow coal resources, the depth of coal mining continues to increase, the impact of karst water hazard on coal production is more prominent. According to the statistic data of Karst water-inrush accidents in China, $80 \%$ of the water-inrush accidents are structural water inrush, and most of them are water inrush from collapse column, for example, water inrush from the world's largest subsided column occurred in Fangezhuang Coal Mine of Kailuan Group in June 1984, water inrush from the subsided column occurred in Dongpang Mine of Xingtai in April 2003, water inrush from the subsided column occurred in Luoshan subsided column of Shenhua Group in March 2010, etc. .[1-6] The water inrush volume in the above water inrush accidents exceeded $1000 \mathrm{~m}^{3} / \mathrm{min}$, which caused great loss to people's lives and property.

The location and water conductivity detection of collapse column are the foundation of treatment, and the method of combination of downhole geophysical exploration and drilling is usually used to detect the location and scope of collapse column.[7] At present, the treatment technology of collapse column mainly includes the closure of roadway, the construction of "water stop plug" , the "three-stage" water plugging of collapse column, direct plugging, backflow grouting and drainage grouting, etc. ${ }^{[6]}$ The development process of control technology can be divided into three stages. The first stage (1984-1996) is represented by 2171 fully mechanized mining face in Fangezhuang Coal Mine of Kailuan Group, which is the first case of water inrush disaster at home and abroad. The treatment technology is to block up the water inrush collapse column by subsection downward grouting. This method has the disadvantages of low drilling precision, large engineering quantity and high cost. In the second stage (1996-2006), the technology of "water plugging" in the collapse column is widely used, that is, building a certain length of "water plugging" in the pre-set layer of the water-inrush column, and cutting off the water inrush channel of the collapse column, such as the 7277 working face collapse column Treatment Project of Wanbei Renlou coal mine. The disadvantage of this method is that it can not control drilling accurately, only "Serpentine" drilling can be used, and the engineering quantity is relatively large. In the third stage (since 2006),

${ }^{*}$ Corresponding author: ccritiangan@126.com 
the Directional branch hole-making technology is widely used, which makes the "water blocking" construction technology in the collapse column more mature and perfect, such as the control project of the water bursting collapse column in 2903 working face of Dongpang coal mine. In this stage, directional drilling technology was used to drill accurately and directionally in the loose body of the collapse column, and a "water plugging" construction technology was formed, in which directional branch drilling was the main method. The exploration precision is greatly improved, and the engineering quantity and the management cost are greatly reduced in this stage.[6,8]

At present, the Directional Branch inclined hole "water plugging" construction technology is mostly used to detect and control the water hazard of many collapse columns. In general, this method has the advantages of small engineering amount, easy to put aggregate, and can be widely used in the stereoscopic detection of subsided columns. This technique is suitable for the application under the condition that the position and boundary of the collapse column are relatively clear. However, due to the limitation of the terrain construction environment, the Directional branch inclined hole "water plugging" construction technology can't be used in this collapse column exploration and treatment project. Combined with the characteristics of site construction conditions, this project adopts a special multi-level multi-branch directional horizontal construction "water blocking" technical method. This method is generally suitable for the collapse column location and boundary conditions are not clear. The prospecting and harnessing technology has a good reference to the structural prospecting and harnessing engineering under similar conditions.

\section{Project design of collapse column exploration and treatment}

\subsection{Survey of the study area}

The TASHAN coal mine of Datong Coal Mine is a coal mine of Datong Coal Field of carboniferous-jurassicseries. The length of 8228 coal face is $3101 \mathrm{~m}$, the dip length is $230.5 \mathrm{~m}$. The average thickness of coal seam is $19 \mathrm{~m}$. According to the analysis of the geological and hydrogeological conditions of the working face, the No. 35 coal seam is $80 \mathrm{~m}$ away from the top of ordovician limestone Aquifer, and the ordovician limestone water pressure in the floor is $1.84 \mathrm{MPa}$. The water inrush coefficient is $0.023 \mathrm{MPa} / \mathrm{m}$, and the working face is in the relative safe zone. At the end of November 2016, water inrush from floor occurred when 8228 working face belt roadway was driven to $2060 \mathrm{~m}$ in two-plate area of Tashan mine. The maximum water volume was about $272 \mathrm{~m}^{3} / \mathrm{h}$ at the heading face, which caused part of the roadway to be flooded, seriously affecting and threatening the safety of mine production. The water level of G1 observation hole in the ordovician limestone aquifer dropped about $60 \mathrm{~m}$ after water inrush occurred in the belt roadway of the working face. Based on the comprehensive analysis of underground electrical method, Rayleigh wave exploration, surface 3D seismic data and controlled source exploration data, the water inrush in the belt roadway of the working face is the water inrush accident in the ordovician limestone aquifer of the coal seam floor caused by the water flowing collapse column in front of driving.[9-10]

In order to find out the development boundary and filling characteristics of the water flowing collapse column in the working face, and to treat the collapse column by Grouting, the comprehensive exploration and treatment of the collapse column based on the technology of directional horizontal drilling on the ground were carried out in the mine[11-12].

\subsection{Exploration and treatment plan of caved column}

The design of the Collapse Column Control Scheme is based on the principle of "side exploration, side treatment and side design", and is guided by the principle of "taking treatment as the main task, combining exploration with treatment, stopping off water and cutting off water sources, and curing water disaster at the root". The goal is to achieve safe mining under pressure in No. 3-5 coal seam and No. 8 coal seam of lower group after treatment of collapse column. According to the geological analysis of the working face, $3-5$ coal seam is $80 \mathrm{~m}$ away from the top of the ordovician Limestone Aquifer, and 8 coal seam is $38 \mathrm{~m}$ away from the ordovician limestone aquifer under the floor.No. 8 coal seam is about $6 \mathrm{~m}$ thick, and 8 coal seam is basically connected with the ordovician limestone aquifer. In order to ensure the follow-up safe mining of 35 and 8 coal seams after grouting treatment of subsided column, the level of grouting treatment of water-flowing subsided column exploration and water-blocking plug construction should be selected from $10 \mathrm{~m}$ to $30 \mathrm{~m}$ above the top of ordovician limestone, and three layers (interval $20 \mathrm{~m}$ ) with 15 branch holes are arranged, of which 10 branch holes are arranged $30 \mathrm{~m}$ below top surface of ordovician limestone and the spacing of branch holes is $40 \mathrm{~m}$. Three branch holes are arranged $10 \mathrm{~m}$ below top surface of ordovician limestone and the spacing of branch holes is $120 \mathrm{~m}$. Two branch holes are arranged on top surface of ordovician limestone and the distance between the branch holes is $160 \mathrm{~m}$. A total of 2 main holes are designed in the ground. Each main hole is constructed with 7-8 branch holes (as shown in fig. 1). At the same time, the water-resisting layer of coal floor in the scope of collapse column is increased and strengthened, and finally the safe mining of coal face is realized.

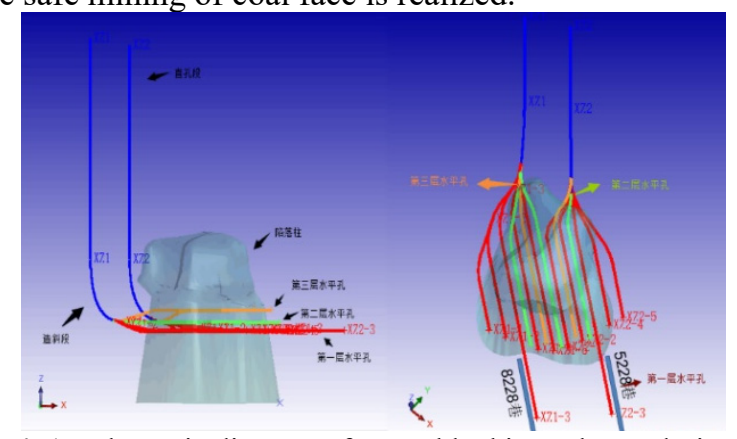

Fig1. Schematic diagram of water blocking scheme design. 


\section{Comprehensive exploration technology of caved-in column based on directional drilling}

\subsection{Microanalysis of borehole cuttings logging}

Cuttings logging is an important technical means to judge formation in directional drilling. In the course of directional drilling, cuttings are taken out of the ground by drilling fluid after the rock is broken, filtered by vibrating screen, and salvaged at regular intervals (generally $2 \sim 4 \mathrm{~m}$ ) .

In the process of exploration, the dense cuttings are retrieved (once for 1 2m) when the branch hole is drilled to the target zone and the ordovician limestone is close to $50 \mathrm{~m}$ outside the geophysical exploration boundary of the collapse column. The cuttings are washed with clear water and dried after they are salvaged. And then the cuttings are initially judged by the naked eye and the method of dilute hydrochloric acid titration dissolution. On this basis, the cuttings are magnified 500 times by electron microscope to identify the lithology of cuttings.

Fig. 2 is a 500x magnification micrograph of a partial branching cuttings microscope. The lithology of drilling formation is distinguished by analyzing the purity and crystal characteristics of cuttings of different lithology in the picture. The normal formation cuttings in the borehole are the same bright white crystal-like lithic cuttings containing dolomite and calcite. The cuttings are mixed cuttings such as gray sandstone, coal and mudstone after the branch hole enters the collapse column. The lithology and color of cuttings are disordered. According to the position distribution of cuttings of each branch hole, the development range of collapse column can be determined (Table 1).
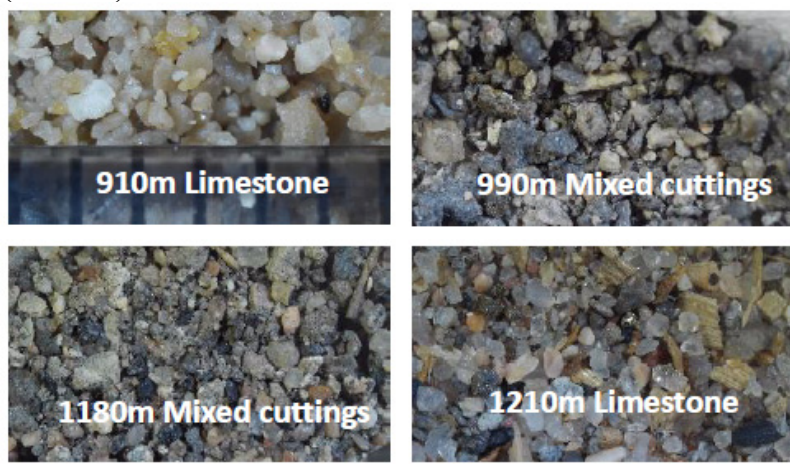

Fig2. Microcrystalline analysis of cuttings from partial branched boreholes.

Table1. A list of the scope of collapse column identified by cuttings of each branch borehole.

\begin{tabular}{|c|c|c|c|}
\hline $\begin{array}{l}\text { Bore } \\
\text { number }\end{array}$ & $\begin{array}{c}\text { Collapse } \\
\text { column range } \\
/ \mathrm{m}\end{array}$ & $\begin{array}{c}\text { Bore } \\
\text { number }\end{array}$ & $\begin{array}{c}\text { Collapse } \\
\text { column range } \\
/ \mathrm{m}\end{array}$ \\
\hline $\mathrm{XZ1-1}$ & $985 \sim 1195$ & $\mathrm{XZ2-1}$ & $1010 \sim 1145$ \\
\hline $\mathrm{XZ1-2}$ & $970 \sim 1185$ & $\mathrm{XZ2-2}$ & $1090 \sim 1195$ \\
\hline $\mathrm{XZ1-3}$ & $988 \sim 1198$ & $\mathrm{XZ2-3}$ & $994.72 \sim 1140$ \\
\hline $\mathrm{XZ1-4}$ & $975 \sim 1175$ & $\mathrm{XZ2-4}$ & $1070 \sim 1155$ \\
\hline $\mathrm{XZ1-5}$ & $975 \sim 1140$ & $\mathrm{XZ2-5}$ & $1062 \sim 1155$ \\
\hline
\end{tabular}

\begin{tabular}{|c|c|c|c|}
\hline XZ1-6 & $960 \sim 1190$ & XZ2-6 & $1110 \sim 1215$ \\
\hline XZ1-7 & $975 \sim 1200$ & XZ2-7 & $975 \sim 1180$ \\
\hline
\end{tabular}

According to the microcrystalline analysis of different lithology cuttings, the length and short axis of the collapse column is $410 \mathrm{~m} \sim 180 \mathrm{~m}$.

\subsection{Analysis of logging data of branch hole while drilling}

During the construction of each branch hole, Gamma logging while drilling was carried out in the exposed formation, and the gamma value suddenly increased when the hole entered the formation such as mudstone from limestone. In this way, the development range of the collapse column can be analyzed and judged by the variation of the gamma curve of the borehole.

Fig. 3 is the logging curve of XZ2-3 branch borehole with drilling. From the XZ2-3 logging-while-drilling curve, it can be seen that the gamma value is less than 100 API when the branch hole is drilled in limestone. But the gamma value suddenly increases to about 250 API when the branch hole is drilled to about $1000 \mathrm{~m}$ depth and enters the collapse column. When the branch hole enters the limestone stratum from the collapse column Broken Body (the hole depth is about $1150 \mathrm{~m}$ ), the gamma value suddenly drops below 100API, the branch hole exits the collapse column boundary and enters the normal limestone stratum. The well logging curves show that the boundary of the collapse column is obvious.

In the same way, the boundary of collapse column can be clearly determined by the curves of other branch boreholes changing with well logging. The length axis of the collapse column is about $335 \mathrm{~m} \sim 220 \mathrm{~m}$.

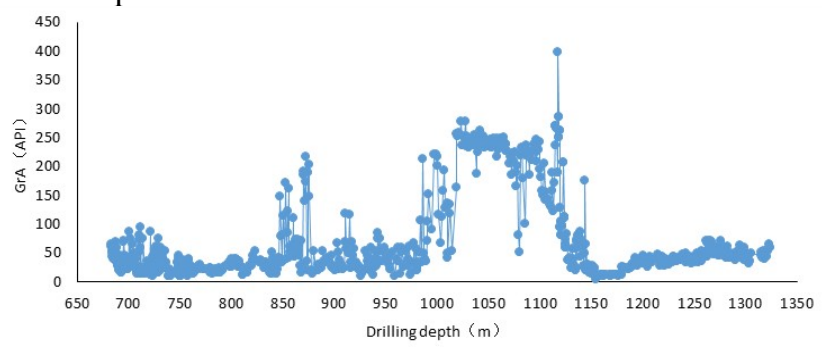

Fig3. Gamma change curve of XZ2-3 branch borehole while drilling.

\subsection{Analysis on variation of drilling speed of branch hole}

To some extent, the speed of drilling reflects the formation integrity and cementation, and the development of voids, pores and fractures. The variation of penetration rate of each branch hole can be used to analyze the broken distribution of the filling material in the collapse column, and to provide a reference for the selection of appropriate grouting technology for mine water disaster control.

Fig. 4 is the time curve of XZ2-2 branch hole drilling. It can be seen from the variation curve of drilling speed of XZ2-2 that the drilling speed reaches $0.5 \mathrm{~m} / \mathrm{min}$ at about $930 \mathrm{~m}$ and $0.3 \mathrm{~m} / \mathrm{min}$ at about $1100 \mathrm{~m}$ depth, which indicates that the formation is relatively broken and the 
degree of cementation is poor in these sections. It is the impact area of collapse column and the developed filling area. In the same way, we can analyze and judge the broken section of formation in the course of drilling by other drilling time curves.

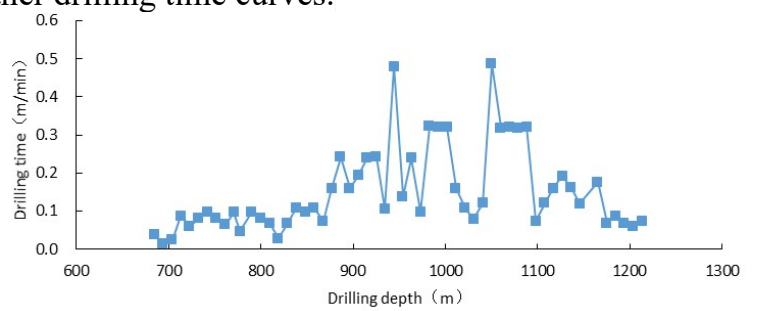

Fig4. Variation curve of drilling time for XZ2-2 branch hole.

\subsection{Analysis of variation of drilling fluid consumption}

In the process of drilling, the amount of drilling fluid consumption to a certain extent reflects the development of formation fractures. The larger the consumption of drilling fluid, the more developed the fractures and fractured the formation. Therefore, the development characteristics of collapse column are analyzed by using the distribution characteristics of drilling fluid consumption of each branch hole.

Fig. 5 shows the curve of drilling fluid consumption during XZ2-1 branch drilling. From the change curve of drilling fluid consumption of XZ2-1 branch hole, it can be seen that the water leakage from the hole suddenly increases and even completely loses when the branch hole is drilled to the sections of $750 \mathrm{~m}, 883 \mathrm{~m}$ and $1010 \mathrm{~m}$ depth, which indicates that the formation is broken and the pores and fractures are developed in these sections, filling cementation difference. In the same way, the section with broken formation and poor cementation can be determined by analyzing the change curve of drilling fluid consumption in other branch holes.

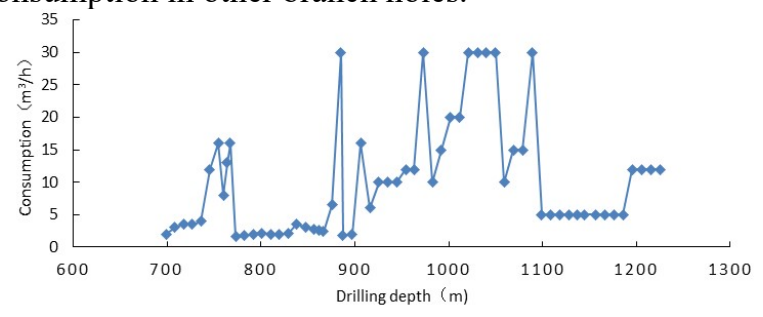

Fig5. Variation curve of drilling fluid consumption in branch of XZ2-1.

\subsection{Comprehensive analysis of development characteristics of collapse column}

Based on the results of directional drilling, it is found that the size of collapse column is $410 \mathrm{~m} \sim 200 \mathrm{~m}$, and the broken area is mainly distributed in the direction of water inrush roadway. Combined with the comprehensive analysis of the ground inclined hole exploration and logging results, some sections of No. 3-5 coal seam moved down $25 \mathrm{~m}$, and some sections of No. 8 coal seam collapsed $55 \mathrm{~m}$. This indicates that the collapse column was formed relatively young, the collapse of the lower strata was carried away by water flow, the collapse was larger than that of the upper strata, and the cavity on the top of the collapse column was not completely formed.

The above exploration results provide a basis for the three-dimensional characterization of the fractured body of the collapse column and the construction of water blocking blocks.

\section{Three-dimensional description and zoning technology of collapse column broken body}

Based on the data of drilling rate and drilling fluid consumption during the exploration of each branch of directional horizontal drilling, a 3D geological model of the Development Section of collapse column is established by using SURPAC software. The fractured body of the collapse column is divided into threedimensional sections (Fig. 6, Fig. 7) according to the distribution characteristics of voids, pores and fractures. The red areas are the areas with high penetration rate and drilling fluid consumption, indicating that the filling body of the collapse column is very broken and the cavities and pores are developed. They are classified as the main passage area. The yellow areas are the areas with high penetration rate and drilling fluid consumption, and the filling body of the collapse column is relatively broken. The green area is the area with small amount of fracture and the fracture is the area with secondary fracture. The main passageway area is cavity and pore-type area, which is the main passageway of water conduction of collapse column. The fracture area is poor cementation area of broken body, and the fracture area is relatively developed. The secondary fracture area is the influence zone of collapse column, and the fracture is not developed.

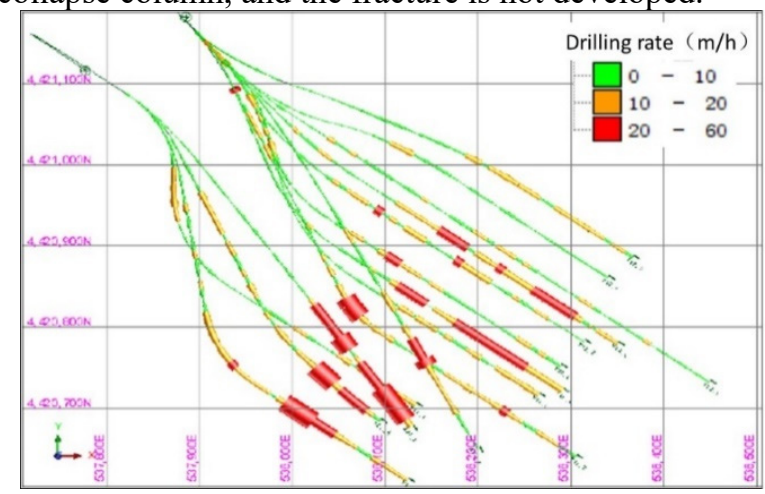

Fig6. Three-dimensional partition map of drilling time of collapse column broken body. 


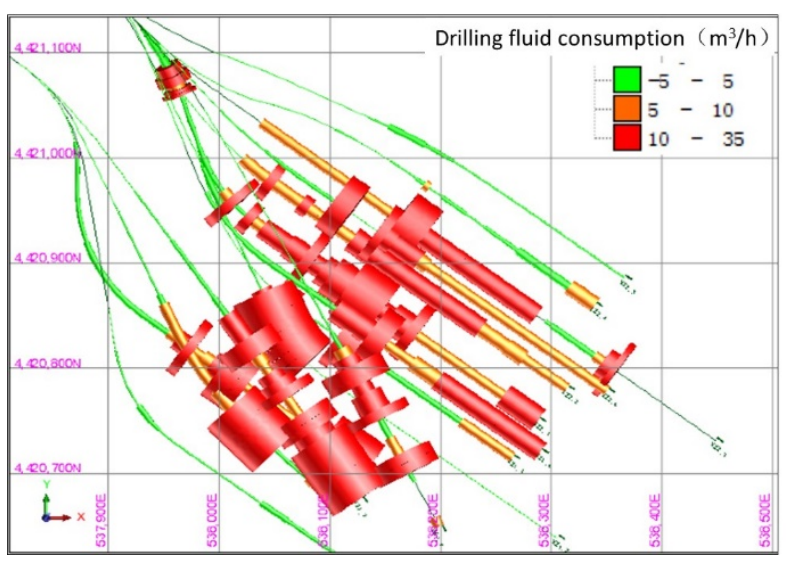

Fig7. Three-dimensional partition map of drilling fluid consumption of collapse column broken body.

\section{Three-dimensional construction tech- nology of water stoppage in collapse column}

\subsection{Selection of grouting technology for water blocking construction}

In the process of directional horizontal drilling comprehensive exploration of collapse column, the area, where each branch hole drilling is located, is analyzed in real time according to the three-dimensional description of the broken body of collapse column. according to the different degree of cementation of filling body in different areas, different grouting techniques such as filling, squeezing and cracking are adopted (such as Table 2), to block the construction of water, and block the water source.

Table2. A list of grouting technology for construction of water blocking plug.

\begin{tabular}{|c|c|c|c|c|}
\hline Grouting area & $\begin{array}{c}\text { Grout } \\
\text { type }\end{array}$ & $\begin{array}{c}\text { Grouting } \\
\text { parameter }\end{array}$ & $\begin{array}{c}\text { Grouting } \\
\text { mode }\end{array}$ & Target \\
\hline passage area & $\begin{array}{c}\text { Cement } \\
\text { fly ash } \\
\text { slurry }\end{array}$ & $\begin{array}{c}\text { No } \\
\text { pressure }\end{array}$ & $\begin{array}{c}\text { Quantitative } \\
\text { grouting, } \\
\text { Intermittent } \\
\text { grouting }\end{array}$ & $\begin{array}{c}\text { Blocking the } \\
\text { main passage } \\
\text { and build the } \\
\text { water blocking } \\
\text { frame }\end{array}$ \\
\hline Fracture area & $\begin{array}{c}\text { Single } \\
\text { liquid } \\
\text { slurry }\end{array}$ & $\begin{array}{c}\text { Slurry } \\
\text { concentration } \\
1.3-1.5\end{array}$ & $\begin{array}{c}\text { Step-up } \\
\text { pressure, } \\
\text { continuous } \\
\text { grouting }\end{array}$ & $\begin{array}{c}\text { Sealing large } \\
\text { fissures and } \\
\text { dissolve them }\end{array}$ \\
\hline Secondary & $\begin{array}{c}\text { Single } \\
\text { liquid } \\
\text { fracture area }\end{array}$ & $\begin{array}{c}\text { Slurry } \\
\text { concentration } \\
1.2-1.3\end{array}$ & $\begin{array}{c}\text { Step-up } \\
\text { pressure, } \\
\text { continuous } \\
\text { grouting }\end{array}$ & $\begin{array}{c}\text { Sealing the } \\
\text { cracks at the } \\
\text { edges }\end{array}$ \\
\hline
\end{tabular}

\subsection{Construction Technology of blocking water plug grouting}

1) Directional precision control drilling technology. The ground directional screw precision drilling technology is adopted in the construction of water-blocking plug, and the directional precision control drilling is carried out on the subarea of collapse column broken body.

2) Three-dimensional construction technology of layered multi-branch blocking water plug. The construction method of blocking water plug is bottom-up, hierarchical, directional and horizontal branch hole construction. Firstly, 30m first-order horizontal branch holes under the top surface of ordovician limestone were constructed, then the second-order horizontal branch holes were constructed, and then $10 \mathrm{~m}$ directional horizontal branch holes under and above the top surface of ordovician limestone were constructed.

3) A variety of grouting process control technology. On the basis of Directional Control of multi-branch hole stereo construction, various grouting materials, slurry ratio and grouting pressure are used to depict different zones according to the fractured body of collapse column in three dimensions, and grouting techniques such as filling, squeezing and cracking are adopted. Threedimensional construction of water blocking is realized.

\subsection{Analysis on construction effect of water blocking plug}

1) The amount of grouting at the end of each branch hole is less than $50 \mathrm{~L} / \mathrm{min}$, and the pressure at the end of the hole is $3 \mathrm{MPa}$ and lasts $30 \mathrm{~min}$. It has reached the end of grouting standard for blocking water plug construction.

2) According to the analysis of the distribution of the order grouting amount of the branch hole, the grouting amount is mainly concentrated in the first order branch holes. The grouting amount of one sequence branch holes accounts for $60 \%$ of the total grouting amount, while the leakage amount of the second sequence holes is small. The results show that the pre-grouting treatment has a good effect on filling and compaction of the fractures and fissures in the collapse column, and plays a key role in the water-blocking construction of the water-flowing collapse column.

3) The water absorption of branch holes injection test is less than $0.011 /(\mathrm{min} \cdot \mathrm{m} \cdot \mathrm{m})$. It met the requirements of treatment, and blocking water plug construction effect is good.

4) The water inrush point has been effectively controlled. The ordovician limestone water level in G1 observation hole has been basically restored, and finally the safe mining of 8228 working face has been realized.

\section{Main conclusions}

The following main conclusions are drawn:

1) The collapse column was carefully explored base on the comprehensive exploration techniques such as surface directional horizontal drilling cuttings microcrystal analysis, penetration rate analysis, drilling fluid loss and logging while drilling data analysis. The size of the collapse column was basically found to be $410 \mathrm{~m} \sim 200 \mathrm{~m}$. The broken zone is mainly distributed in the direction of Lane 2228 in water inrush roadway.

2) The distribution characteristics of voids, pores and fractures in the fractured body of caved column are divided into three-dimensional geological modeling sections by using SURPAC software, which provides a basis for water-blocking grouting construction.

3) According to the different pore development 
characteristics of the fractured body of the collapse column, the precise three-dimensional construction of the water blocking plug of the collapse column is realized by using different grouting techniques in different subareas.

4) The safe and smooth mining of 8228 working face in Tashan mine is realized by blocking water plug solid construction. The comprehensive exploration technology based on the directional horizontal drilling collapse column and the three-dimensional construction technology of blocking water plug have a good reference to similar projects.

\section{References}

1. Yin Shangxian, Wu Qiang, Wang Shangxu. Waterbearing characteristics and hydro-geological models of Karstic collapse columns in north China [J]. Chinese Journal of Rock Mechanics and Engineering, 2005, 24 (1): 77-82.

2. Wu Qiang. Progress problems and prospects of prevention and control technology of mine water and reutilization in China [J]. Journal of China Coal Society, 2014(05): 795-805.

3. Du Bingjian. Fathering practice of hidden water inrush subsided column in Jiulong Coalmine, Fengfeng mining area $[\mathrm{J}]$. Coal Geology of China, 2012(3): 130-131.

4. Shi Xianzhi,Yuan Dezhu,Ge Jungang. On the prevention and control of mine water induced by collapse column in \# 21301 coal face in Chensilou Coal Mine[J].China Coal, 2009(4): 104-105.

5. Wang Zecai,Wu Qiang. On Karst collapse column and tactics of mine water prevention $[\mathrm{J}]$. Geotechnical Investigation \& Surveying, 2002(01):29-30,21.

6. Zhao Suqi, Wu Qiang. Integnted management technology of water guide collapse column looded wells [J] . China Coal, 2004, 30(7):27- 29,6.

7. MENG Zhaoping, YI Wu . Water inrush characteristics of Fangezhuang coalmine field in Kailuan and its geological condition analysis of water inrush from coal seam floor[J] . Chinese Journal of Rock Mechanics and Engineering, 2009, 28(2): 228 -237 .

8. Yin Shangxian, Lian Huiqing, Liu Demin, Yin Huichao. 70 years of investigation on Karst collapse column in North China Coalfield:cause of origin, mechanism and prevention[J]. Coal Science and Technology, 2019, 47 (11): 24-29.

9. Gou Yongquan. Research on grou nd detection and treatment technology of Ordovician limestone water damage in extra-thick coal seam of Carboniferous[J]. Datong Coal Science \&Technology, 2018,161(3):810

10. Xu Xiaohong. Study on Technology of Coal Mine Synergistic Detection of Ordovician limestone Water[J].Coal Technology, 2019,38(10):115-117.

11. Yao Ningping. Development trend of nearly horizontal directional drilling technology in coal mines of China [J]. Coal Geology \& Exploration, 2008 ,36(4) :78-80.

12. Zheng Shitian. Application of ground directional borehole technology to control prevention karst collapsed column water inrush in coal mines[J]. Coal Science and Technology, 2018,46 (7) : 229-233. 